\title{
Elucidation of the response of heavy elements levels to intraperitoneal administration of different gold nanoparticles into rats for period of 3 days in vivo
}

\author{
Mohamed Anwar K. Abdelhalim ${ }^{1 *}$, Mohammed S. Al-Ayed ${ }^{1}$ and \\ Sherif A. Abdelmottaleb Moussa ${ }^{2}$ \\ ${ }^{1}$ Department of Physics and Astronomy, College of Science, King Saud, University, P. O. Box 2455, Riyadh-11451, \\ Saudi Arabia. \\ ${ }^{2}$ Department of Physics, College of Science, Al-Imam Muhammad Ibn Saud Islamic University, P. O. Box 90950, \\ Riyadh, 11623, Saudi Arabia. \\ Accepted 8 September, 2011
}

\begin{abstract}
Nanoparticles (NPs) can potentially cause adverse effects on organ, tissue, cellular, subcellular, and protein levels due to their unusual physicochemical properties. Advances in nanotechnology have identified promising candidates for many biological and biomedical applications. Gold nanoparticles (GNPs) are being increasingly exploited for medical uses and other industrial applications. The aim of the present study was to elucidate the response of heavy elements levels to intraperitoneal administration of different GNPs into rats for period of 3 days in vivo. The experimental rats were divided into normal and 3 groups (G1A, G2A and G3A; G1: $20 \mathrm{~nm}$; G2: $10 \mathrm{~nm}$; G3: $50 \mathrm{~nm}$; A: it means infusion of $0.05 \mathrm{ml}$ of GNPs for 3 days). To investigate the role of GNP size on heavy elements [cadmium (Cd), nickel ( $\mathrm{Ni})$, lead $(\mathrm{Pb})$ and cobalt (Co)] levels in blood and several tissues of rats, $50 \mu \mathrm{l}$ daily dose of 10, 20 and $50 \mathrm{~nm}$ GNPs was intraperitonealy injected into rats for 3 days. $\mathrm{Cd}, \mathrm{Ni}$ and $\mathrm{Pb}$ concentrations significantly increased in blood and all tissues of rats compared with the normal. Different changes were observed with Co concentrations in blood and several tissues of rats. Co concentrations significantly increased with $20 \mathrm{~nm}$ GNPs in blood and kidney tissue of rats compared with the normal while it significantly decreased in heart, lung and liver tissues of rats. 10, 20 and $50 \mathrm{~nm}$ GNPs may be an effective inducer of oxidative stress which was evident by the fact that they caused significant increase in $\mathrm{Cd}, \mathrm{Ni}$ and $\mathrm{Pb}$ concentrations in blood and all tissues of rats compared with the normal. This study suggests that GNPs may interact with proteins and enzymes of the rats interfering with the antioxidant defense mechanism and leading to reactive oxygen species (ROS) generation, which in turn may imitate an inflammatory response and heavy element levels destruction. Exposure to intraperitoneal administration of GNPs is a potential source of oxidative stress toxicity in rats.
\end{abstract}

Key words: Gold nanoparticles, size, severaltissues, blood, heavy elements, toxicity, rats.

\section{INTRODUCTION}

Nanotoxicity is an emerging field of research, a response to growing uses of nanosized materials in a slew of

*Corresponding author. E-mail: abdelhalimmak@yahoo.com or mabdulhleem@ksu.edu.sa. technological applications and consumer products. Moreover, particles of nano-dimension are believed to be more biologically reactive than their bulk counter parts due to their small size and larger surface area to volume ratio (Lanone and Boczkowski, 2006).

In vivo studies in rats exposed to aerosols of GNPs revealed that the NPs were rapidly taken into the system 
with the highest accumulation in the lungs, aorta, oesaphagus and olfactory bulb (Yu et al., 2007).

Gold in its bulk form has long been considered an inert, noble metal with some therapeutic and even medicinal value hence GNPs are thought also to be relatively noncytotoxic (Connor et al., 2005). Yet there are different reports indicating the toxic nature of these particles owing to the different modifications of the GNPs, surface functional attachments and shape and diameter size of the nanospheres (Takahashi et al., 2006; Panet al., 2007).

Elemental metal NPs like cadmium and silver are known to induce oxidative stress and apoptosis in various cell types (Chen and Schluesener, 2008; Arora et al., 2008). In spite of this, the link between GNPs and oxidative stress is not well established. Most often, the harmful effects of reactive oxygen species (ROS) may be manifested through damage of DNA, oxidations of polyunsaturated fatty acids in lipids and oxidations of amino acids in proteins (Limbach et al., 2007), and DNA damage occurs in GNP treated lung fibroblast cells ( $\mathrm{Li}$ et al., 2008).

Cobalt, copper, and other heavy metals are essential heavy elements, but they too are toxic when their concentrations are relatively high. Possible mechanisms of action of these metals might include inhibition of enzymes, denaturation of protein, or increased susceptibility to infection due to immuno-suppression ( $\mathrm{Li}$ et al., 2008; Mayes, 1999; Sternberg, 1996). Significant toxic compounds and heavy elements intake by the body is considered as a potential co-factor in triggering autoimmune diseases (Mayes, 1999; Sternberg, 1996). To our knowledge, there have been no large systematic investigations on the concentration of heavy elements in the body of patients with auto-immune diseases.

Mercury, cadmium, lead, arsenic, antimony and tin are non-essential, toxic elements. They tend to accumulate in food chains and they have long biological half-lives in humans. However, it has yet to be mentioned that heavy elements that are considered toxic can become of nutritional significance under certain circumstances of physiologic stress in animals and humans (Nielsen, 1990). Although some scientists consider NPs as nontoxic, other studies have reported the toxic effects of NPs (Chithrani and Chan, 2007; Pan et al., 2007). Although some NPs may appear to be nontoxic, other cellular mechanisms such as cell signaling and other normal cellular functions may be disrupted and are currently undergoing further investigation. The toxicity of NPs is being addressed by a number of standardized approaches with in vitro, in vivo as well as detailed genomic or biodistribution studies (Hussain et al., 2005; Schrand et al., 2008). The biological activities of NPs should be assessed by multiple cell-based assays with several cell types and multiple doses (Shaw et al., 2008) to confirm the results between laboratories (Lanone et al., 2009), GNPs are used as carriers for the delivery of drugs and genes (Gibson et al., 2007).
The response of several heavy elements levels in blood and several tissues of rats to different GNPs injected intraperitonealy into rats in vivo has not yet fully understood in addition to no reports have been documented before. The present study was carried out to elucidate the effects of intraperitoneal administration of different GNPs on the various heavy elements levels in blood and several tissues of rats in vivo.

\section{MATERIALS AND METHODS}

\begin{abstract}
Animals
Healthy, male Wistar-Kyoto rats obtained from the Laboratory of Animal Center (College of Pharmacy, King Saud University). 8 to12 weeks old (approximately $250 \mathrm{~g}$ body weight) were housed in pairs in humidity and temperature-normalled ventilated cages on a $12 \mathrm{~h}$ day/night cycle. A rodent diet and water were provided. In this study, twenty five rats were individually caged, and divided into normal group (NG: $n=10$ ), group 1 (A: infusion of GNPs of size 20 $\mathrm{nm}$ for 3 days; $n=5$ ), group 2 (A: infusion of GNPs of size $10 \mathrm{~nm}$ for 3 days; $n=5$ ) and group 3 (A: infusion of GNPs of size $50 \mathrm{~nm}$ for 3 days; $n=5)$. All experiments were conducted in accordance with the guidelines approved by King Saud University Local Animal Care and Use Committee.
\end{abstract}

\section{Gold nanoparticles administration}

Dose of $0.05 \mathrm{ml}$ of 10,20 and $50 \mathrm{~nm}$ GNPs was intraperitoneal administered to the rats for a period of 3 days. The rats were anesthetized by inhalation of $5 \%$ isoflurane until muscular tonus relaxed. Blood and several tissues (liver, heart, lung and kidney) were collected from each rat.

\section{Digestion of tissues of the rat}

Several tissues of the rat (liver, heart, lung and kidney) were wet digested with nitric acid and converted into acidic digest solutions for analysis by atomic absorption spectroscopy (AAS). The tissue was freeze dried in order to minimize loss of analytics and to facilitate subsequent sample preparation steps, and then homogenized to a fine powder by ball-milling in plastic containers. Approximately 0.20 to $0.25 \mathrm{~g}$ of powdered tissue was weighed into a Teflon reaction vessel and $3 \mathrm{ml}$ of $\mathrm{HNO}_{3}$ were added. The closed reaction vessel was heated in a $130^{\circ} \mathrm{C}$ oven until digestion was completed. The samples were then diluted to a final volume of 20 $\mathrm{ml}$ with quartz distilled water and stored in $1 \mathrm{oz}$ polyethylene bottles for later AAS analysis.

\section{Atomic absorption spectroscopy measurements}

AAS determines the presence and concentration of heavy elements $(\mathrm{Cd}, \mathrm{Ni}, \mathrm{Pb}$ and $\mathrm{Co})$ in different tissues of rats. The heavy elements absorbed ultraviolet (UV) light when they were excited by heat. The AAS instrument looks for a particular metal by focusing a beam of UV light at a specific wavelength through a flame and into a detector. The sample of interest was aspirated into the flame. If that metal is present in the sample, it will absorb some of the light, thus reducing its intensity. The instrument measures the change in intensity. A computer data system converted the change in intensity into an absorbance. As concentration goes up, absorbance also 


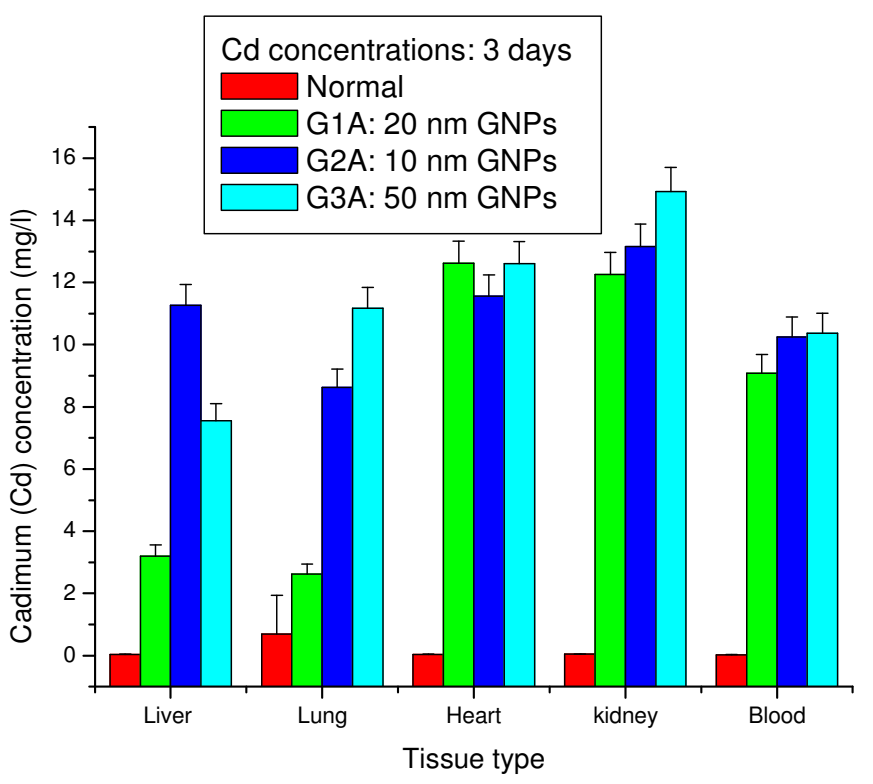

Figure 1. Cadmium concentrations in blood and several tissues of rats after intraperitoneal administration of 10,20 and $50 \mathrm{~nm}$ GNPs for 3 days.

goes up. A calibration curve was constructed by running standards of various concentrations (10, 15 and 20 PPM) on the AAS and observing the corresponding absorbance. A calibration curve was made and then samples were tested and measured against this curve. AAS measurements were carried out at the Research Center for Girls, King Saud University. Cd, Ni, Pb and Co was measured using a Specter AA-220 series double-beam digital atomic absorption spectrophotometer. The concentration of heavy elements in blood and each tissue sample was calculated by comparing the absorbance produced by the sample with that produced by a series of standards as follows:

Concentration of heavy element in the sample $=[$ (Absorbance of Sample/Absorbance of Standard $) \times($ Concentration of Standard)]

\section{RESULTS AND DISCUSSION}

The Cd concentrations significantly increased in blood and all tissues of rats after administration of 10, 20 and $50 \mathrm{~nm}$ GNP for 3 days compared with the normal (Figure 1). The Cd concentrations increased with $10 \mathrm{~nm}$ GNPs in blood, kidney, lung and liver tissues of rats compared with the $20 \mathrm{~nm}$ GNPs. A marked increase in Cd concentrations observed with all GNPs in heart and kidney tissues of rats compared with blood, lung and liver. This demonstrates that, the toxicity induced by increasing $\mathrm{Cd}$ concentrations in kidney and heart tissues was higher than that observed in blood and liver tissues of rats.

The $\mathrm{Ni}$ concentrations significantly increased in blood and all tissues of rats after administration of 10,20 and $50 \mathrm{~nm}$ GNPs for 3 days compared with the normal (Figure 2). The highest increase in $\mathrm{Ni}$ concentration was observed with 10 and $20 \mathrm{~nm}$ GNPs in blood and all tissues of rats compared with $50 \mathrm{~nm}$ GNPs. We have noticed that blood was of less toxicity with $\mathrm{Ni}$ when compared with all other tissues. The $\mathrm{Pb}$ concentrations significantly increased in blood and all tissues of rats after administration of 10,20 and $50 \mathrm{~nm}$ GNPs for 3 days compared withthe normal (Figure 3). Heart tissue was sensitive for $\mathrm{Pb}$ and it may have the most toxicity with lead. We have noticed that nearly equal toxicity was produced in blood and all tissues of rats with $\mathrm{Pb}$ compared with the other heavy elements such as $\mathrm{Cd}$ and $\mathrm{Ni}$.

It is clear from our data that the heavy elements levels such as $\mathrm{Cd}, \mathrm{Ni}$ and $\mathrm{Pb}$ significantly increased in blood and all tissues of rats injected with 10,20 and $50 \mathrm{~nm}$ GNPs compared with the normal. This effect may be attributed to the production of free radicals and/or ROS or hydrogen peroxide radicals which in turn may decrease antioxidant defense enzymes. This study suggests that 10,20 and $50 \mathrm{~nm}$ GNPs may cause oxidative stress due to the toxicity induced by increasing $\mathrm{Cd}, \mathrm{Ni}$ and $\mathrm{Pb}$ concentrations in blood and several tissues of rat.

The study by Li et al. (2010) was in agreement with our conclusion. GNPs treated cells also generated significantly more lipid hydroperoxides a positive indication of lipid peroxidation. Verification with western blot analysis for malondialdehyde (MDA) protein adducts confirmed the presence of oxidative damage. In addition, GNPs treatment also induced up regulation of antioxidants, stress response genes and protein expression. Exposure to GNPs is a potential source of oxidative stress in human lung fibroblasts and autophagy

may be a cellular defense mechanism against oxidative stress toxicity (Li et al., 2010).

Figure 4 shows that Co concentrations induced 


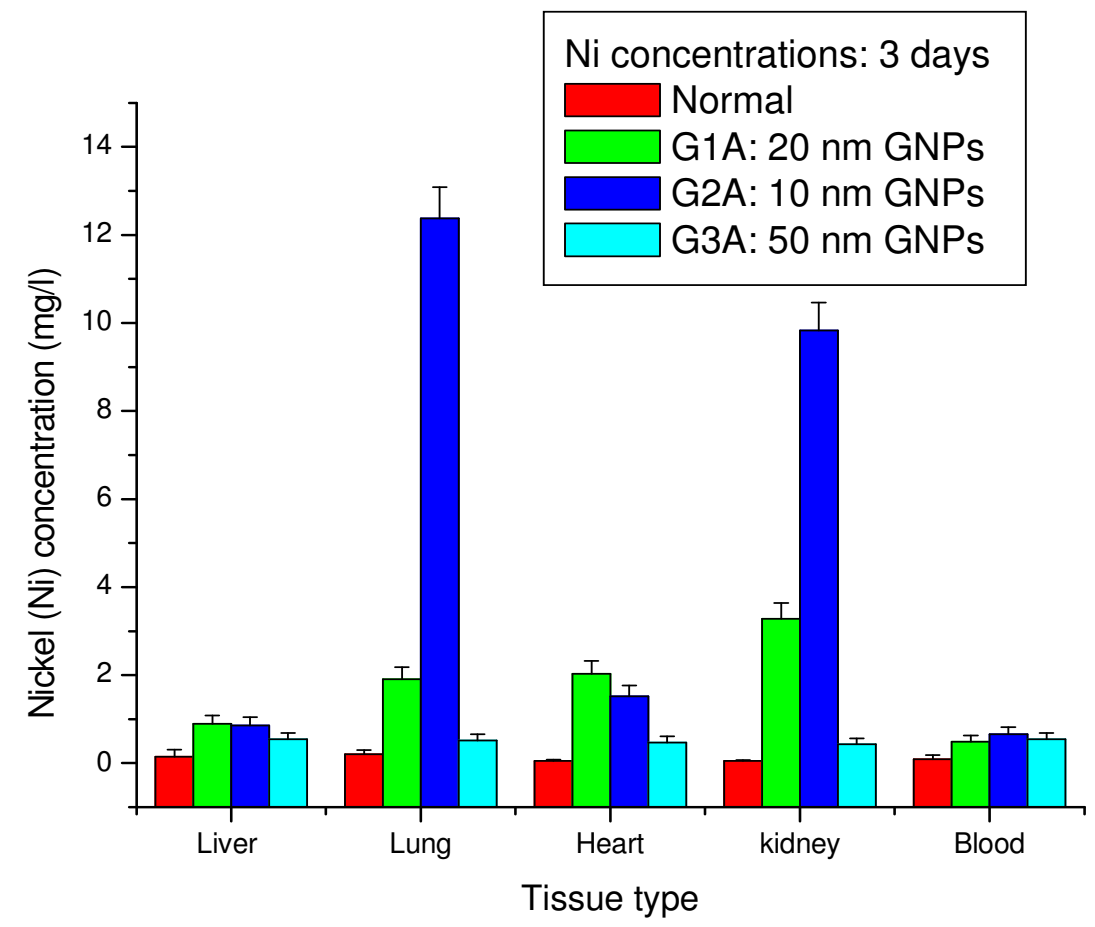

Figure 2. Nickel concentrations in blood and several tissues of rats after intraperitoneal administration of 10, 20 and 50 nm GNPs for 3 days.

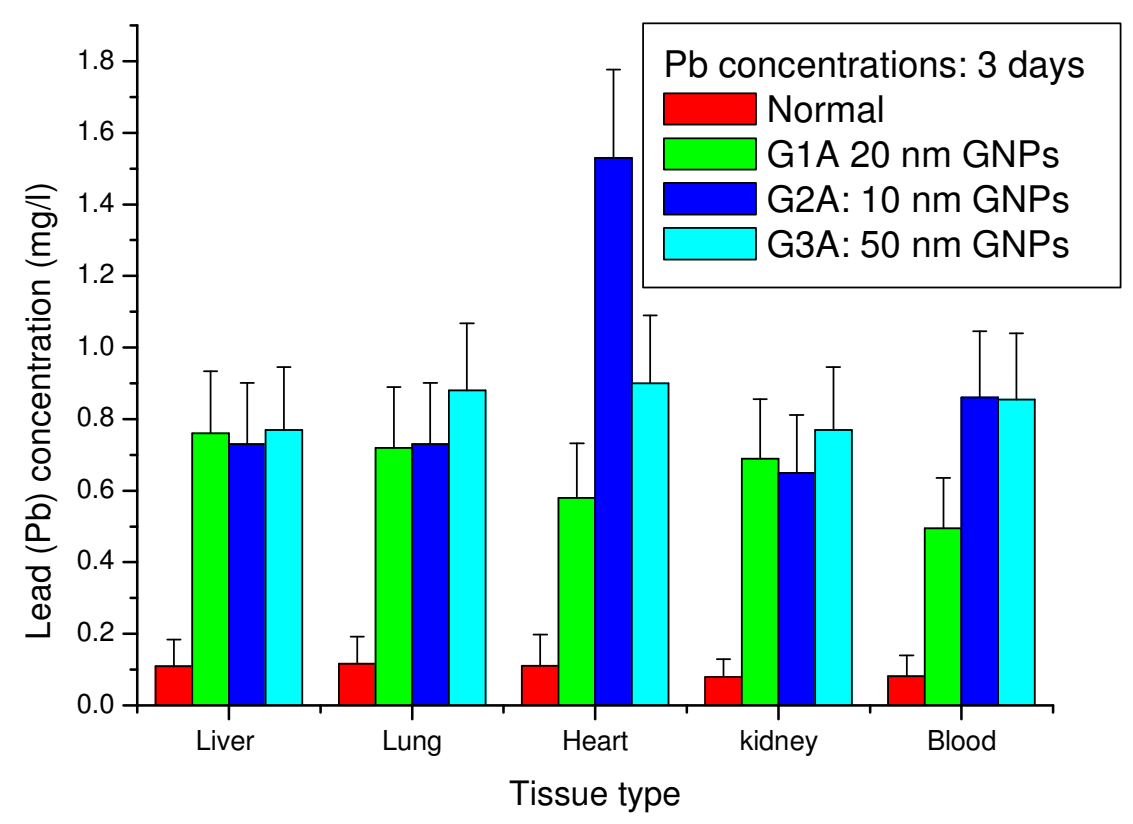

Figure 3. Lead concentrations in blood and several tissues of rats after intraperitoneal administration of 10, 20 and 50 nm GNPs for 3 days.

different changes in blood and several tissues of rats after administration of 10,20 and $50 \mathrm{~nm}$ GNPs for 3 days compared with the normal. Co concentrations significantly increased with 10 and $20 \mathrm{~nm}$ GNPs in blood and kidney compared with the normal while it significantly decreased with all GNPs in the lung tissue of rats. Co concentrations significantly increased with $10 \mathrm{~nm}$ GNPs in blood, heart and kidney tissues of rats compared with the normal while it significantly decreased in lung and liver tissues of rats. Blood is slightly more sensitive for cobalt than other tissues.

GNPs with their small size and large surface area have 


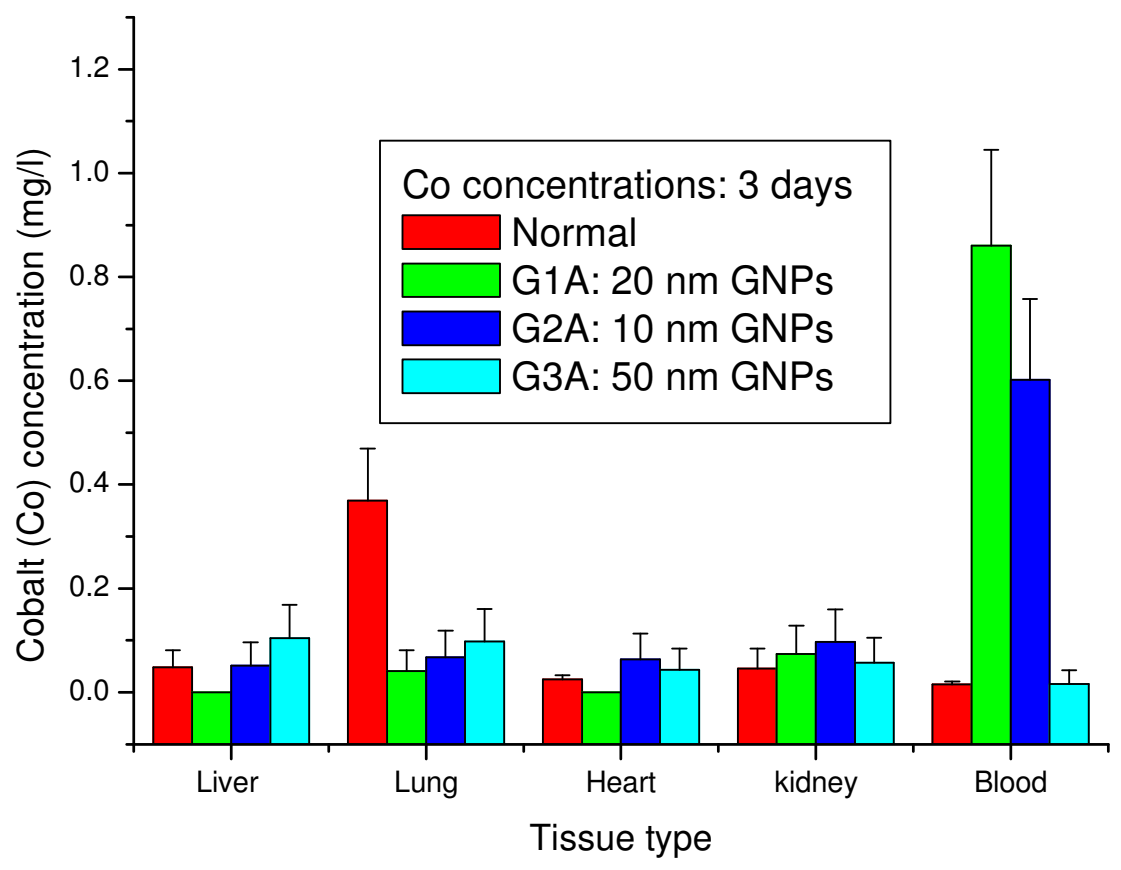

Figure 4. Cobalt concentrations in blood and several tissues of rats after intraperitoneal administration of 10,20 and $50 \mathrm{~nm}$ GNPs for 3 days.

been reported to interact with the proteins (You et al., 2005) and enzymes within mammalian cells and to generate ROS. When the depletion of the antioxidant defense mechanism occurs and ROS accumulate, an inflammatory response can be initiated leading to the perturbation and destruction of the mitochondria resulting in eventual programmed cell death (Schrand et al., 2008; Shaw et al., 2008).

It was proved that the effectual role of GNPs as an antioxidative agent, by inhibiting the formation of ROS, scavenging free radicals; thus increasing the anti-oxidant defense enzymes and creating a sustained normal over hyperglycemic condition which consequently evoke the potential of GNPs as an economic therapeutic remedy in diabetic treatments and its complications (Kanth et al., 2010).

\section{Conclusions}

The 10, 20 and $50 \mathrm{~nm}$ GNPs may be an effective inducer of oxidative stress which was evident by causing significant increase in $\mathrm{Cd}, \mathrm{Ni}$ and $\mathrm{Pb}$ concentrations in blood and all tissues of rats compared with the normal coupled with the increase in Co concentrations with 20 $\mathrm{nm}$ GNPs in blood and kidney tissue of rats compared with the normal. Co concentrations significantly increased with $20 \mathrm{~nm}$ GNPs in blood and kidney tissue of rats compared with the normal; while it significantly decreased in heart, lung and liver tissues of rats.

This study suggests that GNPs may interact with protein and enzymes of the rat interfering with the antioxidant defense mechanism and leading to ROS generation, which in turn may imitate an inflammatory response and heavy element levels destruction. Exposure to intraperitoneal administration of GNPs is a potential source of oxidative stress toxicity in rats.

\section{ACKNOWLEDGEMENTS}

The authors are very grateful to National Plan of Science and Technology (NPST). This research was financially supported by the National Science and Technology Innovation Plan (NSTIP), Research No. 08-ADV206-02 and Research No. 09-NAN670-02, College of Science, King Saud University, Saudi Arabia.

\section{REFERENCES}

Arora S, Jain J, Rajwade JM, Paknikar KM (2008). Cellular responses induced by silver nanoparticles: invitrostudies. Toxicol. Lett., 79 (2): 93-100.

Connor EE, Mwamuka J, Gole A, Murphy CJ, Wyatt MD (2005). Gold nanoparticles are taken up by human cells but do not cause acute cytotoxicity. Small, 1(3): 325-327.

Chen X, Schluesener HJ (2008).Nanosilver: a nanoproductin medical application. Toxicol. Lett., 176: 1-12.

Chithrani BD, Chan WC (2007). Elucidating the mechanism of cellular uptake and removal of protein-coated gold nanoparticles of different sizes and shapes. Nano. Lett., 7: 1542-1550.

Gibson JD, Khanal BP, Zubarev ER (2007). Paclitaxel-functionalized gold nanoparticles. J. Am. Chem. Soc., 129: 11653-11661.

Hussain SM, Hess KL, Gearhart JM, Geiss KT, Schlager JJ (2005). In 
vitrotoxicity of nanoparticles in BRL-3A rat liver cells. Toxicol. in Vitro, 19: $975-983$

Kanth SBM, Kalishwaralal K, Sriram M, Pandian SBRK, Youn H, Eom $\mathrm{SH}$, Gurunathan S (2010). Anti-oxidant effect of gold nanoparticles restrains hyperglycemic conditions in diabetic mice. $\mathrm{J}$. Nanobiotechnol., 8: 16

Lanone S, Rogerieux F, Geys F, Dupont A, Maillot-Marechal E, Boczkowski J, Lacroix G, Hoet P (2009). Comparative toxicity of 24 manufactured nanoparticles in human alveolar epithelial and macrophage cell lines. Part Fiber Toxicol., 6: 14-25.

Lanone S, Boczkowski J (2006). Biomedical applications and potential health risks of nanomaterials: molecular mechanisms. Curr. Mol. Med., 6: 651-63.

Li JJ, Hartono D, Ong C, Bay B, Yung L (2010). Autophagy and oxidative stress associated with gold nanoparticles. Biomaterials, 31: $5996-6003$

Li JJ, Zou L, Hartono D, OngC-N, BayB-H, Yung LYL (2008). Gold nanoparticles induce oxidative damage in lung fibroblasts in vitro. Adv. Mater, 20(1): $138-142$.

Limbach LK, Wick P, Manser P, Grass RN, Bruinin kA, Stark WJ (2007). Exposure of engineered nanoparticles to human lung epithelial cells: influence of chemical composition and catalytic activity on oxidative stress. Environ. Sci. Technol., 41(11): 4158 - 4163.

Mayes MD (1999). Epidemiologic studies of environmental agents and systemic autoimmune diseases. Environ. Health Perspect, 107: 743 748
Nielsen FH (1990). New essential trace elements for the life sciences.Biol. Trace Elem. Res., 599: 26-27.

Pan Y, Neuss S, Leifert A, Fischler M, Wen F, Simon U, Schmid G, Brandau W, Jahnen-Dechent W (2007). Size-dependent cytotoxicity of gold nanoparticles. Small, 3: 1941-1949.

Schrand AM, Bradich-Stolle LK, Schlager JJ, Dai L, Hussain SM (2008). Can silver nanoparticles be useful aspotential biological labels? Nanotechnology, 9: 1-13.

Shaw SY, Westly EC, Pittet MJ, Subramanian A, Schreiber SL, Weissleder R (2008). Perturbational profiling of nanomaterial biologic activity. Proc. Natl. Acad. Sci. USA, 105: 7387-7392.

Sternberg EM (1996). Pathogenesis: environmental. In systemic sclerosis. Clements PJ, Furst DE (eds). Williams \& Wilkins, A Waverly Company, p. 203.

Takahashi H, Niidome Y, Niidome T, Kaneko K, Kawasaki H, Yamada S (2006). Modification of gold nanorods using phosphatidylcholineto reduce cytotoxicity. Langmuir, 22(1): 2-5.

You C, De M, Rotello VM (2005).Monolayer-protectednanoparticleprotein interactions. Curr. Opin. Chem. Biol., 9:639-646.

Yu LE, Yung L-YL, OngC-N, TanY-L, Balasubramaniam KS, Hartono D (2007). Translocation and effects of goldnanoparticles after inhalation exposure in rats. Nanotoxicology, 1(3): 235-242. 